\title{
Differential Transmission of Triticum mosaic virus by Wheat Curl Mite Populations Collected in the Great Plains
}

Anthony J. McMechan, Department of Entomology, Satyanarayana Tatineni and Roy French, United States Department of Agriculture-Agricultural Research Service and Department of Plant Pathology, and Gary L. Hein, Department of Entomology, University of Nebraska-Lincoln, Lincoln 68583-0816

\begin{abstract}
McMechan, A. J., Tatineni, S., French, R., and Hein, G. L. 2014. Differential transmission of Triticum mosaic virus by wheat curl mite populations collected in the Great Plains. Plant Dis. 98:806-810.

Wheat is an important food grain worldwide and the primary dryland crop in the western Great Plains. A complex of three wheat curl mite (WCM)-transmitted viruses (Wheat streak mosaic virus, High plains virus, and Triticum mosaic virus [TriMV]) is a cause of serious loss in winter wheat production in the Great Plains. TriMV was first reported in Kansas in 2006 and later found in most other Great Plains states. Currently, three populations of WCM have been identified by genetic characterization and differential responses to mite resistance genes in wheat. In this study, we examined TriMV transmission by these three WCM populations: 'Nebraska' (NE), 'Montana' (MT), and 'South Dakota' (SD). Mite transmission using single-mite transfers revealed that the NE WCM population transmitted TriMV at $41 \%$, while the MT and SD WCM populations failed to transmit TriMV. In multi-mite

transfers, the NE WCM population transmitted TriMV at 100\% level compared with $2.5 \%$ transmission by MT and SD WCM populations. Interestingly, $\mathrm{NE}$ mites transferred during the quiescent stages following the first and second instar transmitted TriMV at a 39 to $40 \%$ rate, suggesting that immature mites were able to acquire the virus and maintain it through molting. In addition, mite survival for single-mite transfers was significantly lower for NE mites when transferred from TriMV-inoculated source plants $(60 \%)$ compared with mockinoculated source plants (84\%). This demonstrates potentially negative effects on WCM survival from TriMV. TriMV transmission differences demonstrated in this study underscore the importance of identification of mite genotypes for future studies with TriMV.
\end{abstract}

The wheat-mite-virus complex is an important production constraint to winter wheat in the western Great Plains. Average annual losses associated with Wheat streak mosaic virus (WSMV) are estimated at $1 \%(1)$; however, localized yield losses approaching $100 \%$ are not uncommon. The wheat curl mite (WCM), Aceria tosichella Keifer, is the only known vector of the three viruses that make up this wheat-mite-virus complex: WSMV, High plains virus (HPV), and Triticum mosaic virus (TriMV). WSMV was identified in 1922 as "yellow mosaic", and it is the best understood of the viruses within this complex (23). HPV was identified in the 1990s, and it has been difficult to study because it is not mechanically transmissible (12). TriMV was recently identified in wheat in Kansas in 2006 (20) and later found across most Great Plains states $(2,3)$.

To reduce the impact of the wheat-mite-virus complex, wheat varieties have been developed with resistance to both the mite and the viruses they transmit. 'TAM 107' wheat was the first commercial variety released in the late-1980s with resistance to WCM colonization $(17,27)$. The popularity and widespread distribution of this variety led to the development of WCM populations adapted to this mite resistant cultivar $(8,9)$. In addition, Harvey et al. (10) found differences in survival of different WCM collections on resistant varieties with different mite resistance genes.

Carew et al. (5) identified two distinct lineages of WCM (types 1 and 2) in Australia based on a mitochondrial 16S ribosomal DNA (rDNA) gene and two nuclear markers. Schiffer et al. (16) tested

Corresponding author: A. J. McMechan,

E-mail: amcmechan@huskers.unl.edu

The findings and conclusions in this article do not necessarily reflect the view of the United States Department of Agriculture.

Accepted for publication 21 December 2013.

http://dx.doi.org/10.1094/PDIS-06-13-0582-RE

(C) 2014 The American Phytopathological Society the Australian mite types for transmission of WSMV and determined that only one type was able to transmit the virus. Hein et al (11) tested the five mite populations used by Harvey et al. (10) for genetic diversity using polymerase chain reaction (PCR) restriction fragment length polymorphism of mitochondrial and rDNA. Results indicated two distinct mite genotypes similar to Carew et al. (5) mite types. The 'Nebraska' (NE) population (type 2) was genetically distinct from the remaining populations: 'Kansas' (KS), 'Montana' (MT), 'South Dakota' (SD), and 'Texas' (TX) (type 1). Slight differences were observed between MT and other type 1 populations. The magnitude of differences between these type 1 and type 2 WCMs was comparable with the differences between $A$. tosichella and the dry bulb mite, A. tulipae Keifer. However, North American mite types were found to have no significant differences in transmission of WSMV (18). Seifers et al. (18) observed significant differences in transmission of HPV between these North American mite populations. The NE population was shown to be a much better transmitter of HPV than the other mites but the transmission rate for the MT population increased when doubly infected with WSMV (18).

The complete life cycle of the WCM requires 7 to 10 days, with an egg, larva, nymph, and adult stage (23). Just prior to each molt there is a nonfeeding quiescent phase lasting about $18 \mathrm{~h}$ where the mites remain inactive and appear partially translucent (23). WSMV is transmitted by all active stages of the WCM $(6,14,15,21,22)$. Within 15 min of feeding, $1 \%$ of WCMs are capable of acquiring WSMV and longer acquisition times increased the transmission rate. WCM can transmit WSMV for up to 7 days after acquisition at room temperature $\left(23\right.$ to $\left.28^{\circ} \mathrm{C}\right)$ and up to 61 days at $3^{\circ} \mathrm{C}(14)$. Adult WCMs are unable to acquire WSMV but they can transmit the virus if it is acquired during earlier stages of development. Adults were less efficient vectors of WSMV when compared with immature mites (14). In another study, transferring quiescent WCMs from WSMV-inoculated plants resulted in a 94\% transmission rate (21).

TriMV is a plus-sense, single-stranded RNA virus consisting of 10,266 nucleotides with a polyprotein of 3,112 amino acids, and it 
has been placed in the family Potyviridae $(7,26)$. TriMV is the type member of the newly proposed genus Poacevirus. The coat protein of TriMV showed a $45.9 \%$ amino acid sequence identity with Sugarcane streak mosaic virus but only $23.2 \%$ of its amino acid sequence identity with WSMV, the type member of the genus Tritimovirus (7). After the discovery of TriMV in Kansas in 2006, an initial transmission rate was established at $21 \%$ but the WCM type used was unknown (19). However, no additional details concerning TriMV transmission are known.

Transmission efficiency can have implications for future studies that involve WCMs as vectors. Given the differences in HPV transmission between mite types, it is important to determine whether similar differences exist in TriMV transmission. The objectives of this research were to determine the TriMV transmission capabilities by WCMs and compare TriMV transmission efficiencies of different WCM populations collected in the Great Plains.

\section{Materials and Methods}

Maintenance of WCM populations. Three WCM populations designated NE, MT, and SD were used in this study. These mite populations originated from the same populations used to evaluate mite resistance to WCM-resistant wheat varieties (10) and transmission of HPV (18) and to genetically characterize WCMs (11). WCM populations were maintained on 'Millennium' wheat and continuously isolated with cages. Cages were made of plastic sheeting molded to form a $15-\mathrm{cm}$-diameter cylinder. Two $8-\mathrm{cm}-$ diameter holes were cut on opposite sides of the cage approximately one-third of the way up the cage. The top of the cage and side vents were covered with Nytex $(250-\mu \mathrm{m}$ mesh; BioQuip Products Inc.). These avirulent WCM populations were kept in separate growth chambers on a cycle of $14 \mathrm{~h}$ of light and $10 \mathrm{~h}$ of darkness (14L:10D) cycle and maintained at $27^{\circ} \mathrm{C}$. Populations were maintained by transferring approximately 50 mites onto 10 new wheat plants every 2 to 3 weeks.

Mite stage study. Individual virus-infected source plants were established in the greenhouse using Millennium wheat seeded into 4-cm-diameter cone-tainers (Stuewe \& Sons Inc.) filled with standard greenhouse soil. Cone-tainers were covered with plastic cylindrical cages $(5 \mathrm{~cm}$ in diameter and $50 \mathrm{~cm}$ in height) with two to three vents that were covered with Nytex screen.

Fourteen days after seeding, plants at the two- to three-leaf stage were mechanically inoculated with TriMV. To inoculate plants, TriMV-positive tissue was ground in sterilized distilled water at a 1:20 (wt/vol) ratio by using a mortar and pestle. Plants were dusted with carborundum to induce microscopic damage of plant tissue.

One week after inoculation, 20 aviruliferous WCMs were transferred from the NE population onto each of the six source plants. To transfer mites to source plants, the mites were placed onto moist black insect-mounting triangles $(1.3$ by $0.4 \mathrm{~mm})$ with a human eyelash attached to a wooden dowel. Triangles were placed into the axil of the newly emerging leaf of each source plant. To allow mites to become established, plants remained in the lab for approximately 10 to $15 \mathrm{~h}$ following the transfer. Plants were then transferred to a growth chamber with a 14L:10D cycle and maintained at $27^{\circ} \mathrm{C}$. Mites were permitted to build up on source plants for a period of 3 weeks. Source plants were sampled 17 days after inoculation and virus presence was determined by reverse-transcription PCR using forward primer Tr-89 (5'-CAAGATTAACGCGGC ATGG-3') and reverse primer Tr-100 (5'-AACCTCGAGCTAACG GGTACCAAACATGGCCCCGCCGACA- $3^{\prime}$ ) (Integrated DNA Technologies Inc.) with Taq polymerase (Roche). Only five TriMV-positive source plants were used in the study. Mites were permitted to build up on source plants for a period of 3 weeks.

Test plants were seeded 1 week after infesting source plants with mites. One Millennium wheat seed was seeded per cone-tainer and caged immediately. When test plants reached the three-leaf stage (14 days after planting), individual mites were transferred from each source plant onto five test plants for each mite development stage tested. Single-mite transfers were done for quiescent stage one (between larva and nymph), two (between nymph and adult), and adult mites. In addition, 5 and 15 adult mites were transferred from each source plant onto each of five test plants. To transfer mites to test plants, a source plant containing mites was placed under a stereomicroscope. One mite was removed from the source plant using a human eyelash attached to a wooden dowel and, with the aid of an adjacent stereomicroscope, it was placed on the newly emerging leaf of a test plant. After transferring, cone-tainers were then covered with cages and the base sealed with tape. Test plants were arranged in a completely randomized design and held in a growth chamber maintained at $27^{\circ} \mathrm{C}$.

After 3 to 4 weeks, test plants were harvested. Test plants were cut at soil level and examined under a stereomicroscope to determine mite presence, and virus presence was determined by doubleantibody indirect enzyme-linked immunoabsorbent assay (DASELISA).

Single-mite transfers. Virus-infected source plants were established as described in the mite stage study. Half of the plants were inoculated with TriMV and the other half were done in the same manner using only sterilized distilled water (mock inoculation). One week after inoculation, 10 WCMs were transferred from each of three avirulent WCM populations (NE, SD, and MT) onto three TriMV- and three mock-inoculated source plants. Mites were permitted to build up on source plants for a period of 3 weeks. When test plants reached the three-leaf stage (14 days after planting), individual mites were transferred from each source plant onto 10 test plants. The transfer order of the treatment combinations was randomized using SAS (version 9.2.2; SAS Institute 2008). After transferring mites, source plants were placed individually into plastic zip-lock bags and stored at $-20^{\circ} \mathrm{C}$ for subsequent virus assay via DAS-ELISA. Test plants were arranged in a randomized complete block design and held in a growth chamber (14L:10D at $\left.27^{\circ} \mathrm{C}\right)$.

After 3 to 4 weeks, test plants were harvested. Test plants were cut at soil level and examined under a stereomicroscope to classify mite presence. Each test plant was put into individual zip-lock bags and stored at $-20^{\circ} \mathrm{C}$ for virus testing by DAS-ELISA. This procedure was repeated five times (runs) for a total of 15 source plants and 150 test plants per treatment combination.

Multi-mite transfers. Source plants were established using the same procedure as the single-mite transfers, with the exception of planting three plants/cone-tainer. In all, 24 cone-tainers were inoculated with TriMV and 18 cone-tainers were mock inoculated with sterilized distilled water at the two- to three-leaf stage (approximately 14 days). Seven days after inoculation, a source of infected mites was established by transferring 10 avirulent mites onto each of the three source plants in a cone-tainer. Only adults and second instars exhibiting normal movement were transferred. Each WCM population (NE, MT, and SD) was transferred onto eight TriMV cone-tainers and six mock-inoculated cone-tainers. To allow mites to establish on plants, source plants remained in the lab for $10 \mathrm{~h}$ before being transferred to the growth chamber. Mites were permitted to build up on source plants for a period of 1 week.

Test plants were established by planting 10 Millennium wheat seeds at a depth of 1 in. $(2.5 \mathrm{~cm})$ around the outside of each of 21 $15-\mathrm{cm}$ diameter pots, which were then covered with cages. Two empty cone-tainers were buried at a normal depth in the center of each pot and left open for later insertion of infested source cones. This experiment was run once using a completely randomized design, with four replications for TriMV and three replications for mock-inoculated checks for each WCM population.

To infest test plants, two mite-virus source cone-tainers were placed directly into the empty cone-tainers within each pot when test plants were 14 days old. Infestation order and placement of source plants were randomized using SAS (version 9.2.2; SAS Institute 2008). During infestation, leaf tissue (an approximately 5$\mathrm{cm}$ section) was harvested from upper leaves of each source plant within each cone-tainer for ELISA testing. One entire plant was taken from each cone-tainer to determine mite populations. After infesting test plants with mites, pots were returned to the growth chamber (14L:10D at $27^{\circ} \mathrm{C}$ ). Mites were given 4 weeks to move from source plants to test plants. After 4 weeks, all 10 test plants 
were harvested. Mite counts were recorded for each test plant. Test plants were placed individually into plastic zip-lock bags and stored at $-20^{\circ} \mathrm{C}$ for later virus assay by DAS-ELISA.

Testing of test plants by DAS-ELISA. Duplicate samples were tested for TriMV using DAS-ELISA. Positive TriMV controls consisted of wheat tissue inoculated with TriMV, and healthy wheat tissue was used as a negative control. ELISA plates (96-well Flat-Bottom Immuno Plate; Maxisorp, Nunc, Thermo Scientific Inc.) were coated with TriMV immunoglobulin $\mathrm{G}(\mathrm{IgG} ; 25)$ in carbonate buffer at 1:1000 dilution and stored overnight at $4^{\circ} \mathrm{C}$. Each sample was prepared by adding wheat tissue along with general extraction buffer $(100 \mathrm{ml}$ of phosphate-buffered saline with Tween [PBST], $2 \mathrm{~g}$ of polyvinylpyrrolidone [40,000 wt], and $0.2 \mathrm{~g}$ of ovalbumin [crystallized]) at a 1:10 (wt/vol) ratio to a mesh bag (Agdia Inc.). The sample was ground within the mesh bag using a tissue homogenizer (Agdia Inc.). Plant tissue solution $(200 \mu \mathrm{l})$ was added to each of two sample wells of the ELISA plate. TriMV IgG-alkaline phosphate (ALP) conjugate (25) in general extraction buffer (1:500 dilution) was added (100 $\mu \mathrm{l}$ per well). Plates were incubated at $37^{\circ} \mathrm{C}$ for $1 \mathrm{~h}$ and rinsed three times with PBST buffer. Purine nucleoside phosphorylase (PNP) $(100 \mu \mathrm{l})$ was added to each well and incubated in the dark at room temperature for $1 \mathrm{~h}$. Quantitative measurements of the reaction were determined using absorbance at $405 \mathrm{~nm}$ with a Multiscan FC Spectrophotometer (Thermo Scientific Inc.). Plants were considered positive when the absorbance value was greater than $4 \times$ the control.

Mite stage study data for mite presence and virus transmission were analyzed by using PROC GLIMMIX (version 9.2.2; SAS Institute 2008) with a binomial distribution. Different analyses were required for the virus transmission and mite presence data due to the high frequency of zeroes present in the virus transmission data. Virus transmission data from single-mite transfer and multi-mite transfer studies were analyzed using PROC FREQ (version 9.2; SAS Institute 2001) to make pairwise comparisons between populations. An analysis of variance with pairwise comparisons was run on mite presence data for the SMT study to determine differences between WCM populations, inoculation treatments, and their interactions (PROC GLIMMIX version 9.2.2; SAS Institute 2008).

\section{Results}

Mite stage study. The NE population was used to compare TriMV transmission efficiency of the WCM at different stages of

Table 1. Triticum mosaic virus (TriMV) transmission by various wheat curl mite (WCM) populations for single-mite and multi-mite transfer studies

\begin{tabular}{lcc}
\hline & \multicolumn{2}{c}{$\begin{array}{c}\text { Number of positive TriMV plants/total TriMV } \\
\text { transferred plants }(\%)\end{array}$} \\
\cline { 2 - 3 } WCM source & Single-mite transfer & Multi-mite transfer \\
\hline Montana & $0 / 150(0)$ & $1 / 40(2.5)$ \\
Nebraska & $61 / 150(41)$ & $40 / 40(100)$ \\
South Dakota & $0 / 150(0)$ & $1 / 40(2.5)$ \\
$\chi^{2}$ & 141.1311 & 111.4286 \\
$P>\chi^{2 a}$ & $<0.0001$ & $<0.0001$ \\
df & 2 & 2 \\
\hline
\end{tabular}

a Significant differences based on $P$ value of 0.05 in $\chi^{2}$ table. development and infestation levels. Five of the six source plants used in the mite stage study tested positive for TriMV. Additionally, the number of test plants was reduced for each treatment due to low mite populations on source plants during test plant infestation. Virus transmission results indicated that TriMV was maintained through the mite molt. All plants were infected with TriMV using 5-mite $(100 \% ; 21 / 21)$ and 15 -mite $(100 \% ; 18 / 18)$ transfers. The analysis for single-mite transfers of different mite stages found no significant differences for mite presence $(F=1.99, P=0.1928$, $\mathrm{df}=2,12)$ or virus transmission $(F=1.70, P=0.2360$, $\mathrm{df}=2,12)$. The highest transmission rate for the developmental stages was quiescent stage one $(40.0 \% ; 6 / 15)$, followed by quiescent stage two $(39.1 \% ; 9 / 23)$ and adult mites $(15.0 \% ; 3 / 20)$. Two test plants from two separate source plants tested positive for WSMV by ELISA. Due to the low frequency of transmission, it is likely that the WSMV did not originate in the source plants. This study demonstrates the ability of immature and adult NE mites to transmit TriMV, and virus transmission by NE mites transferred in the quiescent stage demonstrates the ability of the virus to be maintained through the molt.

Single-mite transfer. Single-mite transfers were used to compare TriMV transmission efficiencies between WCM populations (NE, MT, and SD). DAS-ELISA results of the 45 source plants and 450 test plants for mock transfers for the three WCM populations were all found negative for TriMV and WSMV, confirming that source mites were avirulent and free of contamination. All 45 TriMV-inoculated source plants tested positive for TriMV (ELISA test ratio $>19 \times$ control) and negative for WSMV (ELISA test ratio $>2 \times$ control). At 3 weeks after infestation, mite populations on all source plants were in excess of hundreds of mites.

There was no significant interaction between run and virus transmission $\left(\chi^{2}=2.14, P>\chi^{2}=0.71, \mathrm{df}=4\right)$. Therefore, data were combined for analysis. Virus assays indicated that neither MT nor SD mites (type 1) transmitted TriMV (Table 1) but NE (type 2) mites transmitted TriMV at a high rate of $41 \%$ (Table 1).

Mite survival following single-mite transfers was reduced for NE mites when transferred from TriMV-inoculated source plants (60\%) compared with mock-inoculated source plants $(84 \% ; F=$ 18.72, $P=0.0007, \mathrm{df}=1$; Table 2). Single-mite transfers from TriMV-inoculated source plants for MT mites (type 1; 79\%) and SD mites (type 1; 75\%) (Table 2) did not exhibit differences in mite presence when transferred from mock and TriMV source plants.

Multi-mite transfer. This study was conducted to determine the potential for low TriMV transmission rates as observed by Seifers et al. (19) by using large numbers of mites for MT and SD populations. Mite counts on source plants at the time of infestation of test plants indicated mite presence of 11 to $153(\bar{x}=74)$ per plant. DAS-ELISA assays indicated that all but 1 source plant (15 of 16; 1 SD negative) tested positive for TriMV. In addition, all source plants tested negative for WSMV. After exposure to the source plants for 3 weeks, all test plants had mites in the range of thousands per plant. Thus, all test plants received extensive exposure to mites for TriMV transmission. All mock source plants and test plants were negative for TriMV, indicating no virus contamination. Under these extreme conditions, NE mites (type 2) transmitted

Table 2. Mite presence on mock- and Triticum mosaic virus (TriMV)-inoculated test plants between populations using single mite transfer

\begin{tabular}{|c|c|c|c|c|c|c|}
\hline \multirow[b]{2}{*}{ WCM source } & \multicolumn{2}{|c|}{ Wheat curl mite (WCM) infested/total plants (\%) } & \multirow[b]{2}{*}{$F$ value $^{\text {a }}$} & \multirow[b]{2}{*}{$\operatorname{Pr}>F$} & \multirow[b]{2}{*}{ Num df } & \multirow[b]{2}{*}{ Den df } \\
\hline & Mock & TriMV & & & & \\
\hline Montana & $123 / 150(82 \%)$ & $115 / 150(76 \%)$ & 0.35 & 0.5619 & 1 & 14 \\
\hline Nebraska & $126 / 150(84 \%)$ & $90 / 150(60 \%)$ & 18.72 & 0.0007 & 1 & 14 \\
\hline South Dakota & $120 / 150(80 \%)$ & $114 / 150(76 \%)$ & 1.32 & 0.2700 & 1 & 14 \\
\hline$F$ value $^{\mathrm{a}}$ & 0.13 & 3.72 & $\ldots$ & $\ldots$ & $\ldots$ & $\ldots$ \\
\hline $\operatorname{Pr}>F$ & 0.8815 & 0.0327 & $\cdots$ & $\ldots$ & $\cdots$ & $\ldots$ \\
\hline Num df & 2 & 2 & $\ldots$ & $\ldots$ & $\ldots$ & $\ldots$ \\
\hline Den df & 42 & 42 & $\ldots$ & $\ldots$ & $\ldots$ & $\ldots$ \\
\hline
\end{tabular}

a Value obtained from $F$ test, $\alpha=0.05$. 
TriMV to $100 \%$ of the test plants but MT and SD (type 1) mites transmitted at a much lower rate of $2.5 \%$ (Table 1 ).

\section{Discussion}

This study demonstrates that TriMV is differentially transmitted by the WCM types. When using single-mite transfers, TriMV was only transmitted by NE (type 2) mites at a transmission rate of $41 \%$. Type 1 (MT and SD) mites were unable to transmit TriMV except when very high mite numbers were used, and then only at a low rate. Seifers et al. (19) determined that the transmission rate of TriMV by the WCM was approximately $21 \%$; however, the type of WCM used in the study was not determined. Our data suggest that they were not likely type 2 WCMs. Successful transmission of TriMV by mites transferred as quiescent stage I and II suggests that TriMV can be carried through both molts of the WCM.

According to the classification of virus transmission mechanisms summarized by Hogenhout et al. (12) and $\mathrm{Ng}$ and Falk (13), virus retention through molting is a characteristic of persistent transmission. However, other qualifying characteristics of virus transmission categories that they list (e.g., acquisition access period, retention time, latent period, and inoculation access period) have not been determined for TriMV. Previous studies with WSMV also determined that the virus was retained through molting; however, unlike other persistent plant viruses, WSMV could be acquired within minutes of feeding (14). This raises questions concerning the classification of viruses transmitted by the WCM. Previous classifications of virus transmission mechanisms have been developed using Hemipteran insect-virus models, and they may not be appropriate for classifying mite-transmitted viruses. Future studies are needed to more completely characterize transmission mechanisms for mite-transmitted viruses.

Mite survival was significantly lower for mites transferred from TriMV-inoculated source plants. Further studies will need to be conducted to determine the impact of TriMV on the biology of the WCM. Siriwetwiwat (21) demonstrated that WSMV presence significantly increased the reproductive rate for type 2 but not type 1 WCMs.

Studies on the transmission of HPV demonstrated differential transmission by these same mite types. Seifers et al. (18) showed that NE (type 2) mites were the most efficient vector of HPV. We also identified type 2 as the most efficient vector of TriMV. A comparison of the two studies indicates that type 2 WCMs had a substantially higher TriMV transmission rate than HPV. In Seifers et al. (18), 10 type 2 mites were used per test plant. with an HPV transmission rate of $44 \%$; a similar TriMV transmission rate $(41 \%)$ was obtained in this study using single-mite transfers. When type 2 mites were increased to five per test plants, $100 \%$ of plants became infected with TriMV.

The populations used in this study were derived from the same populations Seifers et al. (18) used to determine mite transmission of HPV and Hein et al. (11) used to genetically characterize these mite populations as type 1 and type 2 mites. Seifers et al. (18) also demonstrated that HPV transmission was significantly higher for MT mites when source plants were co-infected with WSMV. Further studies are needed to determine differences in TriMV transmission with WSMV co-infected plants.

TriMV and WSMV have been shown to have a synergistic impact on the virus titer in infected plants in greenhouse trials (24), increasing the potential for economic impact in field situations (4). This study indicates that the economic impact of this virus complex may vary relative to the abundance and type of mites present. Siriwetwiwat (21) tested the genetic variability of WCM types in the field and found mixed populations of mites (both type 1 and type 2). The study also found significant genetic variability of mites occurring even within a wheat head.

A survey of symptomatic plants from nine states in the Great Plains indicated that TriMV was widespread throughout the region (2). A survey by Byamukama et al. (3) showed that the overall incidence across the central Great Plains (Colorado, Kansas, Nebraska, and South Dakota) was highest for WSMV (35\%) and low- est for TriMV (6\%) and HPV (4\%). The current study suggests that part of the reason for the varied frequency of TriMV may be its reliance on type 2 mites for transmission. This study also demonstrated a significant reduction in survival of type 2 mites when transferred from TriMV-infected plants. This could have significant epidemiological implications for the spread of TriMV but further studies are needed to verify these potential impacts.

The results from this study contribute to our understanding of the epidemiology of TriMV. The importance of mite type when evaluating TriMV transmission studies is documented; therefore, studies conducted in a field setting should also consider the types of mites present because this may differentially impact the rate of virus transmission and subsequent epidemiology.

\section{Acknowledgments}

Funding for this work was provided by the Agriculture and Food Research Initiative Competitive Grants Program Grant Number 2010-85605-20546 from the National Institute of Food and Agriculture. We thank S. Wegulo and R. Wright for the critical reading of the manuscript and S. Harvey for her contributions to the mite stage study on the transmission of TriMV.

\section{Literature Cited}

1. Appel, J. A., DeWolf, E., Bockus, W. W., and Bowden, R. L. 2012. Preliminary 2012 Kansas wheat disease loss estimates. Kans. Coop. Plant Dis. Surv. Rep. http://www.kdsa.gov/includes/document_center/plant_protection/ Plant_Disease_Report/2012KSWheatDiseaseLossEstimates.pdf

2. Burrows, M., Franc, G., Rush, C., Blunt, T., Ito, D., Kinzer, K., Olson, J., O'Mara, J., Price, J., Tande, C., Ziems, A., and Stack, J. 2008. Occurrence of viruses in wheat in the Great Plains region. Plant Health Progress. Online publication. doi:10.1094/PHP-2009-0706-01-RS

3. Byamukama, E., Seifers, D. L., Hein G. L., De Wolf, E., Tisserat, N. A. Langham, M. A. C., Osborne, L. E., Timmerman, A., Wegulo, S. N. 2012. Occurrence and distribution of Triticum mosaic virus in the central Great Plains. Plant Dis. 97:21-29.

4. Byamukama, E., Tatineni, S., Hein, G. L., Graybosch, R. A., Baenziger, P. S., French, R., and Wegulo, S. 2012. Effects of single and double infections of winter wheat by Triticum mosaic virus and Wheat streak mosaic virus on yield determinants. Plant Dis. 96:859-864.

5. Carew, M., Schiffer, M., Umina, P., Weeks, A., and Hoffmann, A. 2009 Molecular markers indicate that the wheat curl mite, Aceria tosichella Keifer, may represent a species complex in Australia. Bull. Entomol. Res. 99:479-486.

6. Del Rosario, M. S., and Sill, W. H., Jr. 1965. Physiological strains of Aceria tulipae and their relationships to the transmission of wheat streak mosaic virus. Phytopathology 55:1168-1175.

7. Fellers, J. P., Seifers, D. L., Ryba-White, M., and Martin, T. J. 2009. The complete genome sequence of Triticum mosaic virus a new wheat-infecting virus of the high plains. Arch. Virol. 154:1511-1515.

8. Harvey, T. L., Martin, T. J., and Seifers, D. L. 1995. Survival of five wheat curl mite, Aceria tosichella Keifer (Acari: Eriophyidae), strains on mite resistant wheat. Exp. Appl. Acarol. 19:459-463.

9. Harvey, T. L., Martin, T. J., Seifers, D. L., and Sloderbeck, P. E. 1995. Adaptation of wheat curl mite (Acari: Eriophyidae) to resistant wheat in Kansas. J. Agric. Entomol. 12:119-125.

10. Harvey, T. L., Seifers, D. L., and Martin, T. J. 1999. Survival of wheat curl mites on different source of resistant in wheat. Crop Sci. 39:1887-1889.

11. Hein, G. L., French, R., Siriwetwiwat, B., and Amrine, J. W. 2012. Genetic characterization of North American populations of wheat curl mite and dry bulb mite. J. Econ. Entomol. 105:1801-1808.

12. Hogenhout, S. A., Ammar, E., Whitfield, A. E., and Redinbaugh, M. G. 2008. Insect vector interactions with persistently transmitted viruses. Annu. Rev. Phytopathol. 46:327-359.

13. Ng, J. C. K, and Falk B. W. 2006. Virus-vector interactions mediating nonpersistent and semipersistent transmission of plant viruses. Annu. Rev. Phytopathol. 44:183-212.

14. Orlob, G. B. 1966. Feeding and transmission characteristics of Aceria tulipae Keifer as vector of wheat streak mosaic virus. Phytopathol. Z. 55:218238.

15. Paliwal, Y. C., and Slykhuis, J. T. 1967. Localization of wheat streak mosaic virus in the alimentary tract of its vector, Aceria tulipae K. Virology 32:344-353.

16. Schiffer, M., Umina, P., Carew, M., Hoffmann, A., Rodoni, B., and Miller, A. 2009. The distribution of wheat curl mite (Aceria tosichella) lineages in Australia and their potential to transmit wheat streak mosaic virus. Ann. Appl. Biol. 155:371-379.

17. Sebesta, E. E., and Wood, E. A. 1978. Transfer of greenbug resistance from rye to wheat with X-rays. Agron. Abstr. 70:61-62.

18. Seifers, D. L., Harvey, T. L., Louie, R., Gordon, D. T., and Martin, T. J. 2002. Differential transmission of isolates of the High plains virus by different sources of wheat curl mites. Plant Dis. 86:138-142.

19. Seifers D. L., Martin, T. J., Harvey, T. L., Fellers, J. P., and Michaud, J. P. 
2009. Identification of the wheat curl mite as the vector of Triticum mosaic virus. Plant Dis. 93:25-29.

20. Seifers, D. L., Martin, T. J, Harvey, T. L., Fellers, J. P., Stack, J. P., RybaWhite, M., Haber, S., Krokhin, O., Spicer, V., Lovat, N., Yamchuk, A., and Standing, K. G. 2008. Triticum mosaic virus: a new virus isolated from wheat in Kansas. Plant Dis. 92:808-817.

21. Siriwetwiwat, B. 2006. Interactions between the wheat curl mite, Aceria tosichella Keifer (Eriophyidae), and wheat streak mosaic virus, and distribution of wheat curl mite biotypes in the field. Ph.D. dissertation, University of Nebraska, Lincoln.

22. Slykhuis, J. T. 1955. Aceria tulipae Keifer (Acarina: Eriophyidae) in relation to the spread of wheat streak mosaic. Phytopathology 45:116-128.

23. Staples, R., and Allington, W. B. 1956. Streak mosaic of wheat in Nebraska and its control. Univ. Neb. Coll. Agric. Exp. Stn. Res. Bull. 178.
24. Tatineni, S., Graybosch, R. A., Hein, G. L., Wegulo, S. N., and French, R. 2010. Wheat cultivar-specific disease synergism and alteration of virus accumulation during co-infection with wheat streak mosaic virus and Triticum mosaic virus. Phytopathology 100:230-238.

25. Tatineni, S., Sarath, G., Seifers, D. L., and French, R. 2013. Immunodetection of Triticum mosaic virus by DAS- and DAC-ELISA using antibodies produced against coat protein expressed in Escherichia coli: potential for high-throughput diagnostic methods. J. Virol. Methods 189:196-203.

26. Tatineni, S., Ziems, A. D., Wegulo, S. N., and French, R. 2009. Triticum mosaic virus: a distinct member of the family Potyviridae with an unusually long leader sequence. Phytopathology 99:943-950.

27. Thomas, J. B., and Conner, R. L. 1986. Resistance to colonization by the wheat curl mite in Aegilops squarrosa and its inheritance after transfer to common wheat. Crop Sci. 26:527-530. 